\title{
EXTRACT FROM THE FOREWORD OF THE CATALOGUE IN 1925
}

Two previous complete catalogues were published in 1903 and 1905. Except for a large number of unlisted dissertations a third complete catalogue was issued as a separate pamphlet in 1910; lists supplementary to this appeared for the next three years in the Annual Register, but since 1913 financial stress made the issue of further lists impossible. The accessions during these twelve and one-half years have been numerous, but are known to only a few members of the Society who may have visited its Library. That the location not only of these accessions, but also of the hundreds of foreign dissertations long in the Society's possession, might be more generally known, the Council decided that a new and complete catalogue of the Library should be published without further delay. The last complete catalogue was the one published more than twenty years ago, when there were 2,035 volumes in the Library. The present catalogue as of May 1, 1925, lists 6,798 volumes.

The development of the Library has really taken place within less than twenty-five years. When Professor Smith assumed office as Librarian in January, 1902, there were only 121 volumes in the Library and 64 periodicals on the exchange list. Five years later there were 2,549 volumes and 167 exchanges, and by 1912 these figures had been augmented to 3,871 and 180 respectively. When Prufessor Smith resigned at the end of 1920, even these totals were materially increased, as we may observe in the table given below. The Society must ever feel under obligation to the able Librarian during these nineteen years for his zealous and timely activity leading to such remarkable results. 